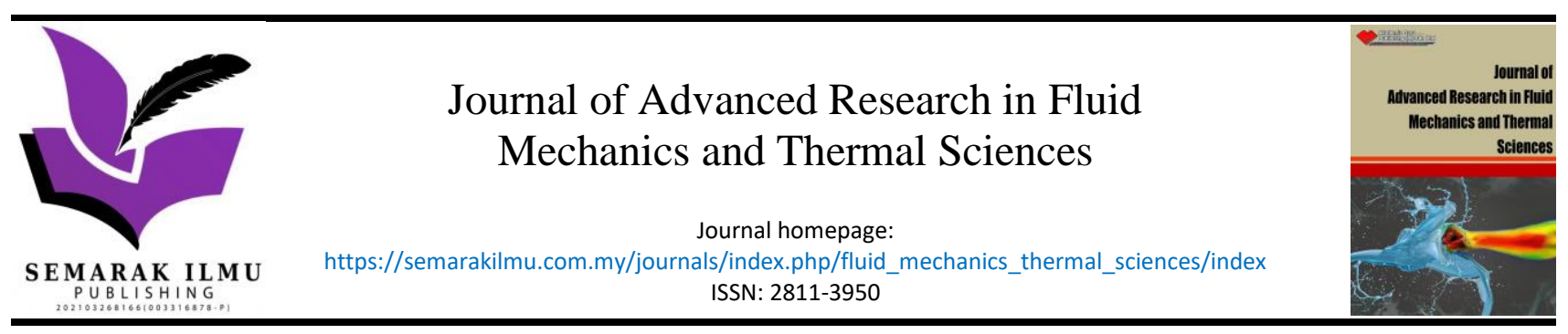

\title{
Self-Desalination Seawater Jig Based on Solar Thermal Energy
}

\author{
Khairul Anuar Abd Wahid ${ }^{1,}{ }^{*}$, Ilham Fahmi ${ }^{1}$, Zaid Puteh ${ }^{1}$, Muhammad Nur Farhan Saniman ${ }^{1}$, Kamal \\ Rusulan $^{1}$, Khairul Azhar ${ }^{1}$, Wan Mansor Wan Muhammad ${ }^{1}$ \\ 1 Universiti Kuala Lumpur, Mechanical Engineering Section, Malaysia France Institute, 43650 Bandar Baru Bangi, Selangor, Malaysia
}

ARTICLE INFO ABSTRACT

\section{Article history:}

Received 27 July 2021

Received in revised form 14 November 2021

Accepted 3 December 2021

Available online 20 January 2022

Keywords:

Self-desalination seawater; water treatment; heat energy; latent heat

\begin{abstract}
In this study, a new design of self-desalination seawater device by applying solar thermal energy has been proposed and characterized. Investigations were conducted to determine whether the fabricated device able desalinate saltwater efficiently. A custom-designed reflector with fixed and adjustable angle configurations was also included and both will be evaluated in terms of performance. The temperature, salinity, and conductivity of the saltwater during the desalination process were measured and compared from 9 am to $3 \mathrm{pm}$. The temperature averagely increases $20.5^{\circ} \mathrm{C}$ for 6 hours exposure. A device with an adjustable reflector able to confine the highest temperature which is up to $58^{\circ} \mathrm{C}$. It was also shown that the heat energy grows proportionally with increasing temperature. A device with reflector shown able to confine the maximum heat energy which is $131.51 \mathrm{~kJ}$ which is $51.75 \%$ higher than without reflector. As a result, the latent heat required to convert salt water to steam decreased from $3.591 \mathrm{~kJ} / \mathrm{kg}$ to $3.538 \mathrm{~kJ} / \mathrm{kg}$. In this regard, the fabricated device able to reduce the seawater salinity from $7651 \mathrm{ppm}$ to $123 \mathrm{ppm}$, which a substantial 98 percent reduction. This result indicates that the proposed device with adjustable reflector can desalinate and convert saline water into safe drinking water.
\end{abstract}

\section{Introduction}

Thousands of people, including fishermen, tourists, and others who have been trapped in the ocean for an extended period due to accident or survival-related circumstances, are believed to have died from dehydration. Although the ocean covers more than $71 \%$ of the Earth's surface and contains $96.5 \%$ of the world's water, only $3.5 \%$ of freshwater is safe to drink [1]. Due to high salt concentration, seawater is not safe to drink. Reportedly, seawater has a salt content of about 3.5 percent, which is equivalent to 35 grammes of dissolved salt in one litre of water [2]. Drinking seawater with such a high salt concentration defeats the purpose of hydrating the body and instead leads to severe dehydration and death [3]. It has been reported that the drinkable of water must contain less than $1000 \mathrm{ppm}$ (parts per million/Mg/L) of total dissolved solids (TDS). Higher than that is not drinkable.

\footnotetext{
* Corresponding author.

E-mail address: khairulanuarabdwahid@unikl.edu.my
}

https://doi.org/10.37934/arfmts.91.1.92101 
The World Health Organization (WHO) has stated that salinity of drinkable water should below 500ppm.

Desalination is a process that removes salt minerals from seawater. There are many types of desalination techniques. One of the techniques known as reverse osmosis (RO). RO principally is a water purification process that uses a partially permeable membrane to separate ions, unwanted molecules, and larger particles from drinking water. However, RO relies on reversing the flow of osmosis by applying a hydraulic pressure. The pressure from hydraulic must be greater than the osmotic pressure of solution, thus forcing water to move from a high-solute region to a low-solute region through a semi-permeable non-porous membrane [4]. This limits the practicality of desalination device during emergency. Another technique is electro dialysis (ED) which is employed mature membrane process to remove the salt from the seawater. However, ED technique required the DC electric field to allow the ion exchange membranes to selectively transfer the anions and cations [5]. Previous researchers also explore on thermal energy to desalinate the seawater [6,7]. In basis, the thermal energy mechanism is the applying heat transfer between different system [8-10]. By using this principle, thermal desalination technique uses thermal energy to vaporize seawater, which is then captured and condensed to produce pure water $[11,12]$. Thermal desalination technique has some advantages over other seawater desalination processes, such as greater reliability, longer life, and less need for raw water [13]. There are many techniques that can be applied thermally such as using a solar cell to heat the heating coil $[14,15]$. However, the solar cell is not efficient enough to generate high power to operate the heater due to the surface area limitation [16]. In addition, the complicated interface circuit may not be suitable in seawater [17]. Another technique that able to generate heat is by using a direct electrical power to heat the coil. However, in the middle of the ocean and in an emergency, electric power is most likely not available.

Hence, the most practical method to generate heat in the middle of the ocean is to use a direct thermal energy from sun or also known as solar thermal energy. The basis is to uses the heat from sun to evaporate the seawater [18]. However, the challenge is to trap the heat from sun as high as possible so that the trapped temperature (latent heat) has enough energy to evaporate the seawater.

Therefore, the main challenge in this project is to design a unique emergency device that can desalinate the seawater and produce pure water with salinity less than $0.5 \mathrm{~g} /$ litre or less than $500 \mathrm{ppm}$. Therefore, the device must be carefully designed to contain the heat at an optimal level without compromise with the authentic appearance, portable, simple, and independent of electrical power.

\section{Methodology}

This project consists of two steps, namely the design and fabrication of the device and the experimental work.

\subsection{Design and Fabrication}

The design plays an important role in the development of the jig desalination system. The design must have a certain criterion to improve the evaporation rate as well as to ensure optimum exposure to sun. In this paper, the design is sketched using Solid-works software. Stainless steel is selected as the main material because it is easy to work with, has good heat absorption properties and reflects light. 


\subsection{Experimental Work}

Experimental work was carried out to investigate the performance of the desalination device. The device containing seawater was exposed to sun from 9 am to $3 \mathrm{pm}$. The effect of the reflector at a fixed and adjustable angle on the performance of the desalination rate and the purity of the water was measured using a salinity meter. The latent heat is then calculated to correlate with the experimental result. Note that the reflector angle was set perpendicular to the solar irradiance angle by using the conventional trigonometry of solar angle elevation based on the shadow of the objects. Figure $1(a)$ to Figure 1 (d) below shows the experimental setup for this project.

During temperature acquisition, the ambient temperature and humidity were measured to ensure that the initial temperature was similar for each experiment. The apparatus was exposed to temperature measurement for 2 hours prior to acquisition. This ensures that the heat is evenly distributed throughout the device after it has been exposed to sun.
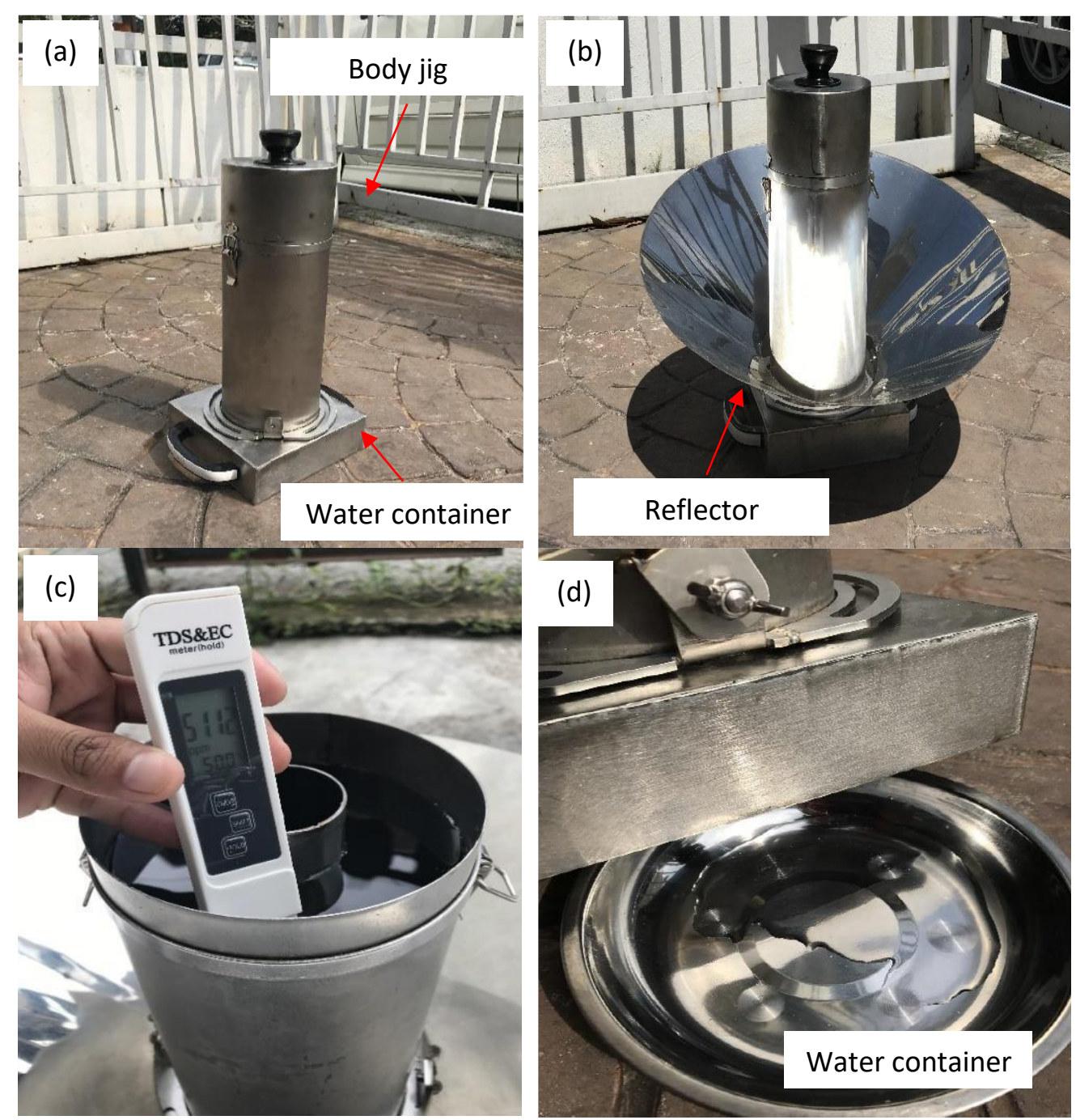

Fig. 1. Experiment Setup of the fabricated jig: (a) Body parts without reflector, (b) Body parts with reflector, (c) Measuring the temperature and (d) Collecting the desalinated water

The amount of heat absorbed by each of these devices will be calculated. It was known that the heat energy can be formulated as follows. 
$Q=m c \Delta T$

Where $Q$ is heat energy, $m$ is mass, $c$ is capacity of water (seawater) and $\Delta T$ is change of temperature. Amount of energy required to raise $1 \mathrm{~g}$ of water by $1^{\circ} \mathrm{C}$. Meanwhile, the latent heat formula can be formulated as follow

$Q=m \Delta H_{v}$

Where $\mathrm{Q}$ is the heat of vaporization, $\mathrm{m}$ is the mass of sea water, and $\Delta H_{v}$ is the latent heat of vaporization. The latent heat is the amount of energy required to change the phase of $1 \mathrm{~kg}$ of material, and hence the unit is joules per kilogram. In this case, this energy is required to change from liquid to vapor during the evaporation process.

\subsection{Mechanism of Desalination Process}

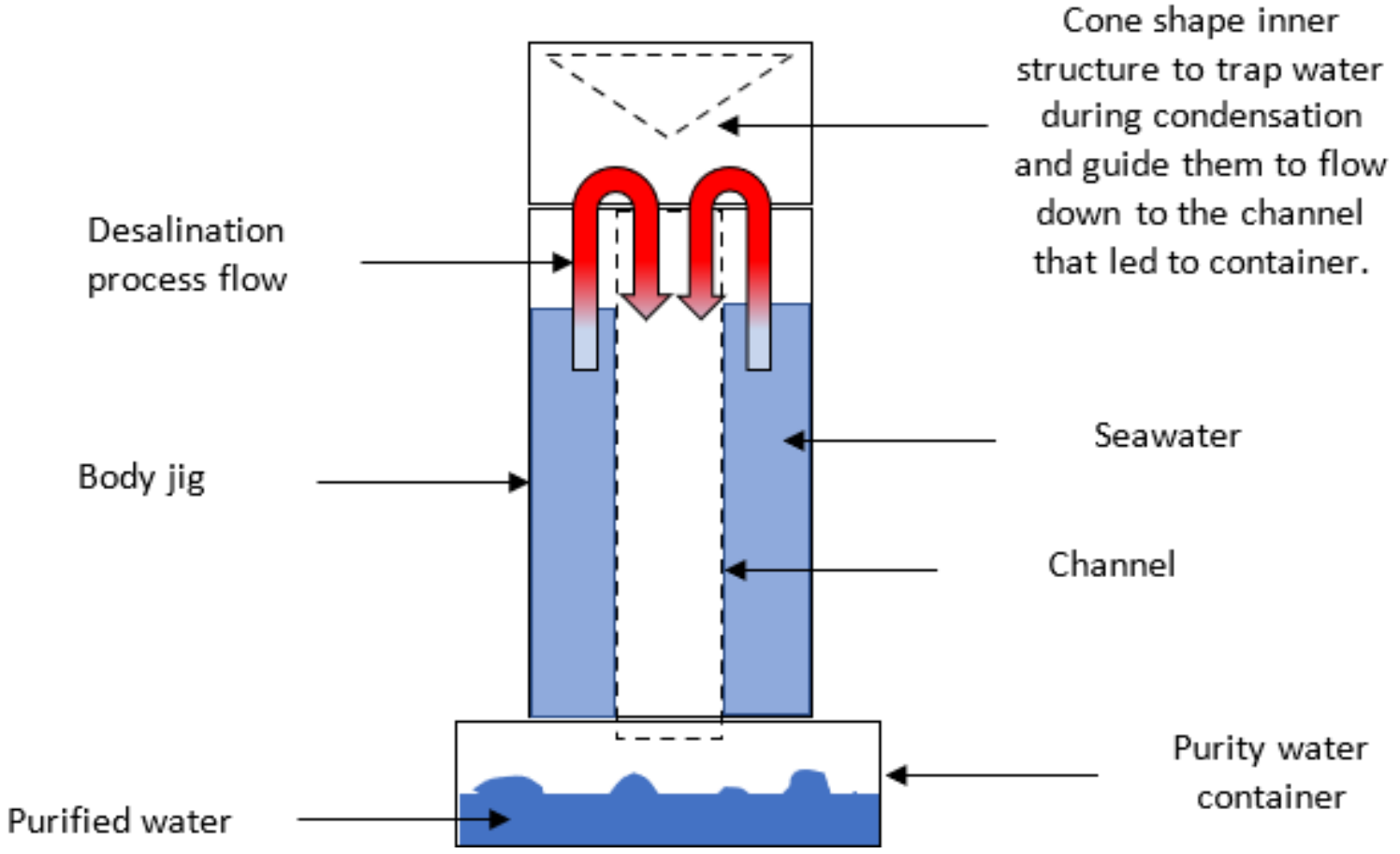

Fig. 2. Mechanism of desalination process

Figure 2 above shows the mechanism of the desalination process. The device will be exposed to sun, which transfers the heat via the radiation principle. Since the body of the device is made of stainless steel, the heat energy is trapped and then efficiently transferred to the seawater as the seawater has direct contact with the stainless-steel surface inside the device. Continuous exposure to sun further increases the temperature inside the body, which can provide enough energy to evaporate the seawater and then condense it in the cone shape. In the cone shape, the thermal energy including latent heat is released, which in turn transforms it into a drop of water. Since the cone shape is tilted at $45^{\circ}$, it directs the water droplets downward into the channel to the purified water tank. The adjustable reflector that fits into the body of the device focuses more sunlight, which further increases the surface temperature on the device. As a result, more heat energy is captured, which in turn increases the efficiency of the desalination process. 


\section{Results}

\subsection{Design and Fabrication}

Figure 3 below shows the overall concept of the design and manufactured device, the material of which is based on stainless steel. Figure 3(a) shows the diameter of the jig part that will contain the seawater. The jig parts have a thickness of $1 \mathrm{~mm}$ and a height of $272 \mathrm{~mm}$. At the bottom of the device, there is a container where the evaporated and desalinated seawater is stored. Figure 3(b) shows the sketch of the reflector which is integrated with the device parts. The height of the reflector is 135 $\mathrm{mm}$, while the diameter is $249 \mathrm{~mm}$, and the diameter of the bottom reflector is $82 \mathrm{~mm}$. A thread is provided at the bottom of the reflector so that the angle of the reflector can be adjusted. Figure 3(c) shows the actual device that was made.

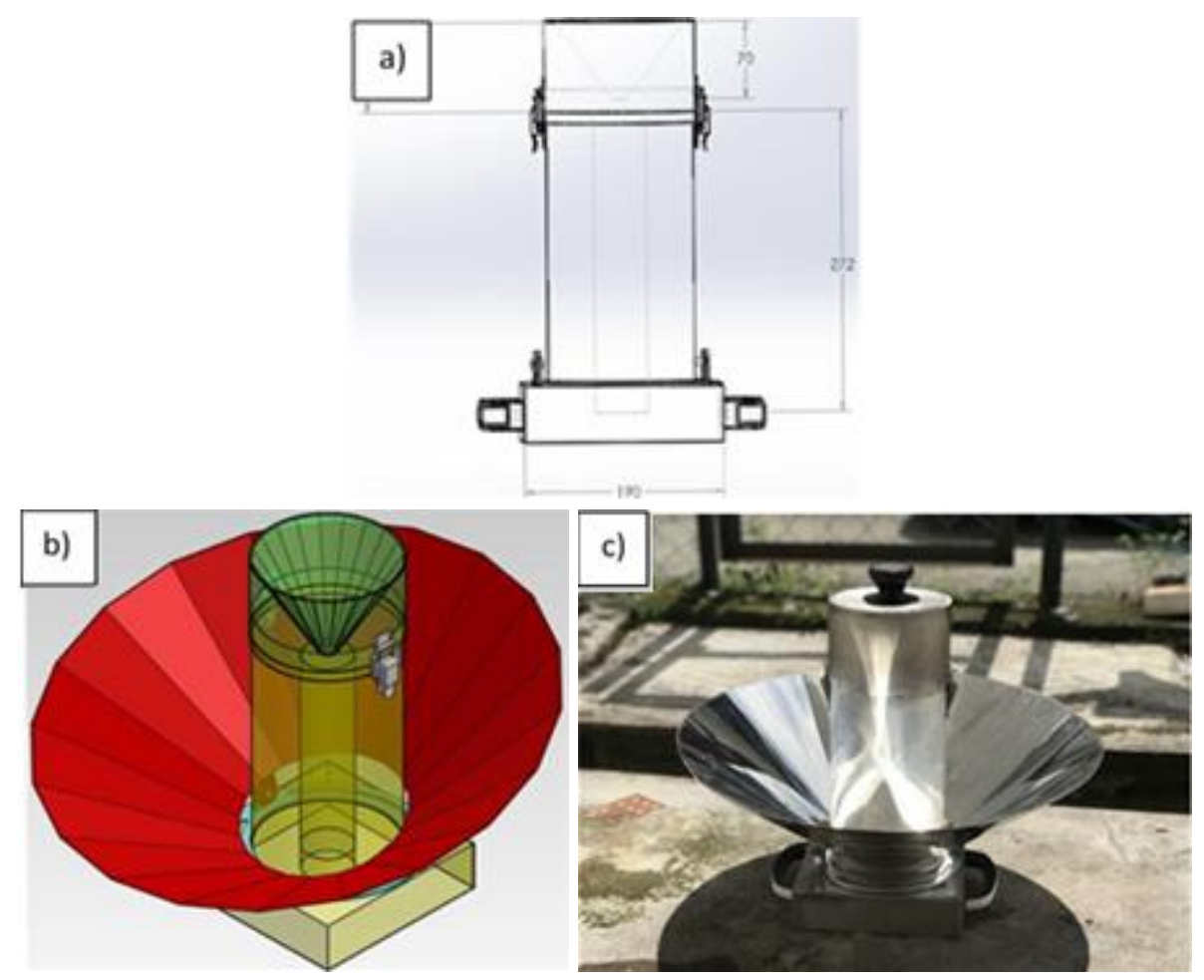

Fig. 3. The design and fabrication of desalination jig (a) Jig part, (b) Concept of reflector been integrated to the jig part and (c) Actual jig that has been fabricated

\subsection{Experimental Result}

The device was filled with 1 litre of the powder and exposed to sunlight in an open space to capture the sun's heat energy. Figure 4 below shows the results of the water temperature inside the device from the morning, $9 \mathrm{am}$, to the evening, at $3 \mathrm{pm}$. In general, the temperature inside the device increases proportionally from morning to evening. For the jig without reflector, the temperature was $30^{\circ} \mathrm{C}$ at the beginning and reached $50^{\circ} \mathrm{C}$ at $3 \mathrm{pm}$. For the jig with fixed reflector, it is $33^{\circ} \mathrm{C}$ in the morning and $53^{\circ} \mathrm{C}$ in the evening. The fixture with adjustable reflector shows the most effective design as the measured temperature is $35.5^{\circ} \mathrm{C}$ at $9 \mathrm{am}$ and reaches $58^{\circ} \mathrm{C}$ at $3 \mathrm{pm}$. It was found that the jig with fixed reflector generally has a higher temperature, which means a temperature difference of $13 \%$ compared to the jig without reflector. On the other hand, the fixture with adjustable reflector exhibits the highest temperature, which is $16 \%$ difference compared to the fixture without reflector. 
These results indicate that the device with adjustable reflector can restrict the temperature more efficiently compared to the other designs.

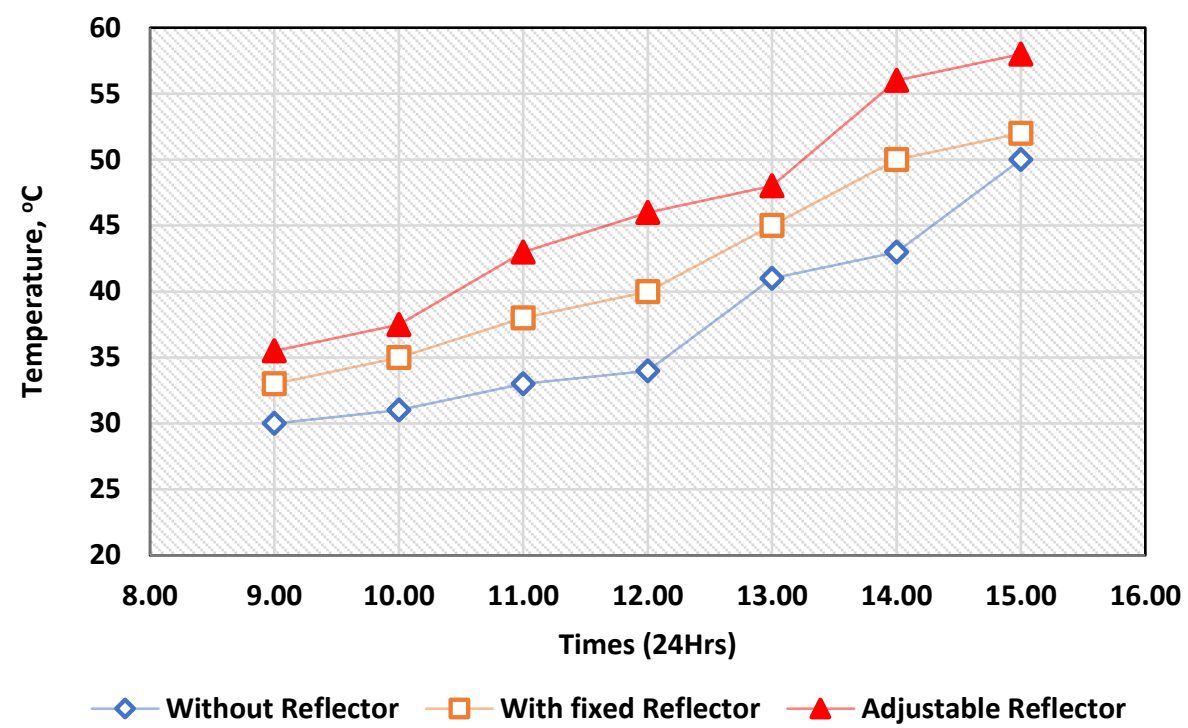

Fig. 4. Temperature measured inside the jig

Figure 5 shows the comparison of salinity in ppm of seawater and desalinated water, respectively. Note that in this experiment the desalinated water is obtained using a device with an adjustable reflector. The sea water was measured using a salinity meter and the reading was $7561 \mathrm{ppm}$ initially and dropped to $123 \mathrm{ppm}$ after desalination. This value is $24.6 \%$ lower than the maximum salinity of acceptable drinking water. This result shows that the device with adjustable reflector can desalinate fresh water with high purity. The graph also shows that the desalinated water has a comparable purity level with mineral water, which has $123 \mathrm{ppm}$ and 69ppm, respectively.

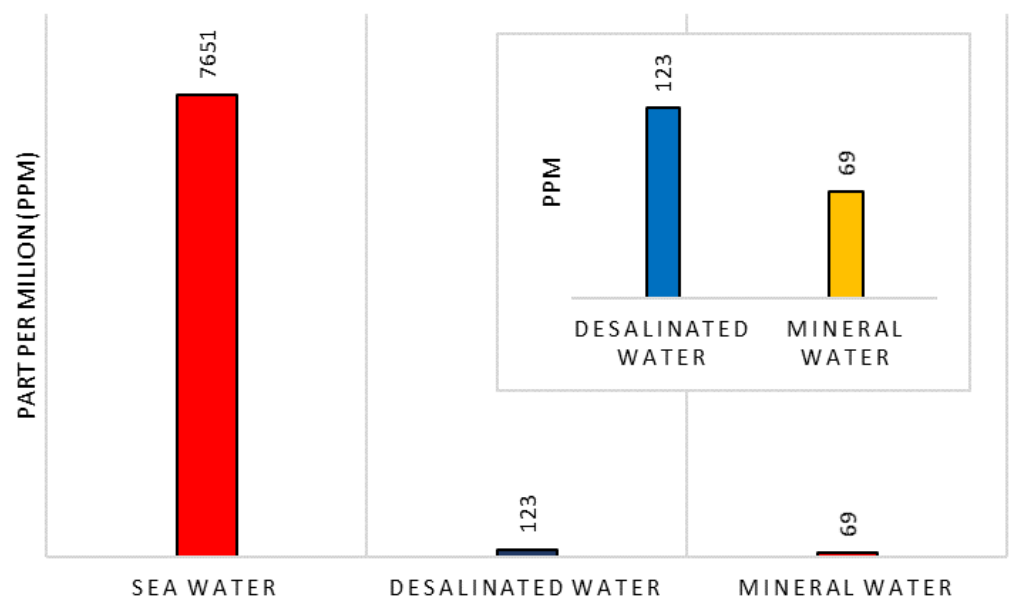

Fig. 5. ppm level of desalinated seawater

It was known that seawater was conductive. Figure 6 below shows the readings of $\mu \mathrm{s} / \mathrm{cm}$ indicating the conductivity of the seawater before and after desalination. In this experiment, the conductivity of the seawater decreased from $11935 \mu \mathrm{s} / \mathrm{cm}$ to $192 \mu \mathrm{s} / \mathrm{cm}$, which is a decrease of more than $98 \%$ after desalination. The conductivity of desalinated water is also comparable to that of mineral water which is $192 \mu \mathrm{s} / \mathrm{cm}$ and $107 \mu \mathrm{s} / \mathrm{cm}$ respectively. This indicates that the designed setting machine able to desalinate the water efficiently. 


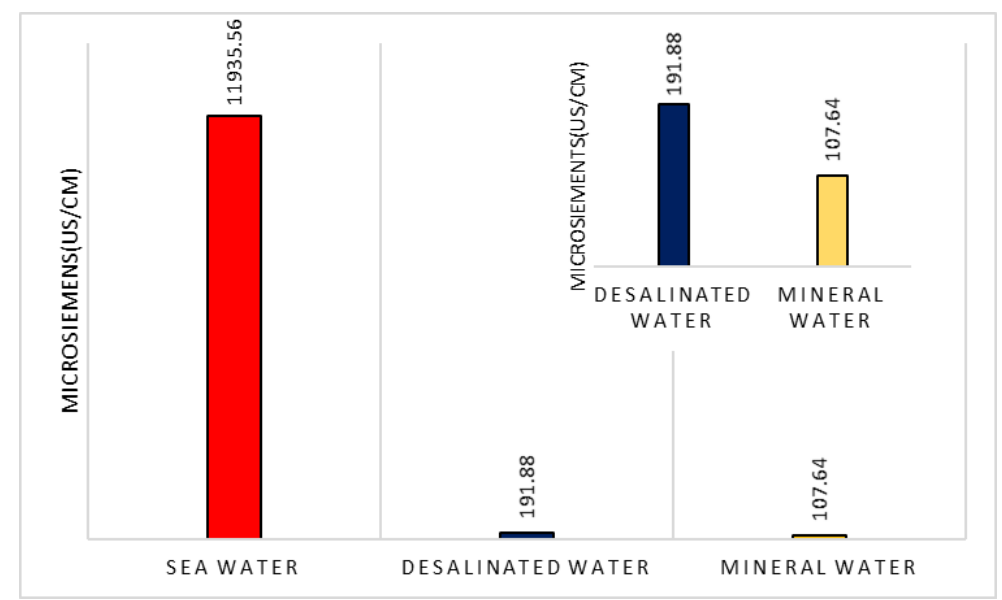

Fig. 6. Micro-siemens $(\mu \mathrm{S} / \mathrm{cm})$ of desalinated water

In the desalination process, seawater must be heated to a certain temperature before the water evaporates. To heat the water, heat energy is needed to raise the temperature of the water. The temperature of the water is further increased until it reaches a certain temperature so that the process of evaporation can take place. In this experiment, the heat energy from the sunlight is collected by the device using the radiation principle and absorbed by the water in the device. The heat energy will then increase the temperature of the water. Since the device consists of three parts, namely the device itself, the fixed reflector and the adjustable reflector, the amount of heat absorbed by each of these devices has been calculated. Figures 7 shows the comparison of heat energy collected by each device. By using Eq. (1), the thermal energy for the setting device without reflector, the setting device with fixed reflector, and the setting device with adjustable reflector are $41.84 \mathrm{KJ}$, $119.55 \mathrm{KJ}$, and $131.51 \mathrm{KJ}$, respectively. This shows that the device with adjustable reflector can contain the highest thermal energy, which is $51.72 \%$ higher than the device without reflector. This indicates that the device with adjustable reflector is the most efficient design to contain the heat from solar thermal energy. This is reflected in the amount of water trapped, which is $11.65 \mathrm{~g}, 33.72$ g, and $37.17 \mathrm{~g}$, respectively.

A further investigation has been carried out to calculate the latent heat of generate by each device. Latent heat can be understood as energy that will need to change the state of substance. In this work, to change the state of water form into steam. Eq. (2) has been applied to calculate the latent heat. Figure 8 shows the comparison of latent heat of each device. It was shown that the latent heat required to change the state of water to steam are $3591.99 \mathrm{~kJ} / \mathrm{kg}, 3545.57 \mathrm{~kJ} / \mathrm{kg}$, and 3538.35 $\mathrm{kJ} / \mathrm{kg}$ for the device without reflector, fixed reflector device and adjustable reflector device, respectively. This indicates that the device with adjustable reflector requires less latent heat compared to the other embodiments in which justify the efficiency of adjustable reflector to enhance further the desalination device performance. 


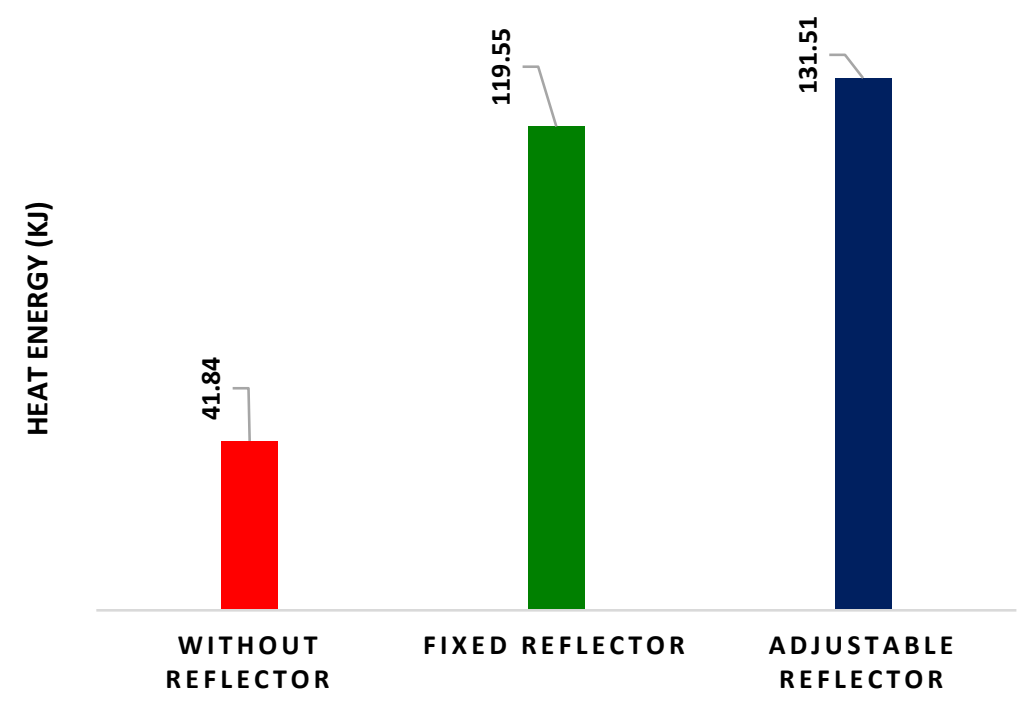

Fig. 7. The comparison of heat energy collected by device

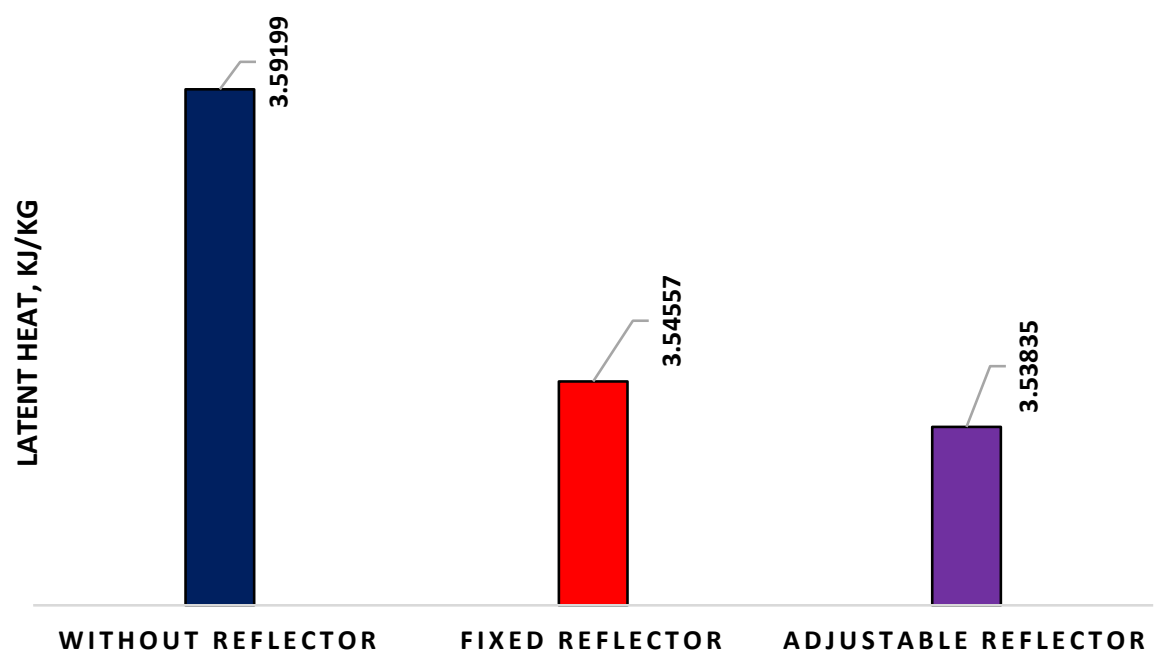

Fig. 8. The comparision of latent heat obtained by device

\section{Conclusions}

The proposed desalination device has sufficient and reliable operation to provide adequate quantity and quality of fresh water. The desalination device can be operated for an average of 6 hours per day. No serious technical problems were found during the operation of the plant, but there may be a need to improve the tracking of the solar angle to make the plant more efficient. It was shown that a device with adjustable reflector can limit the highest temperature, which is $58^{\circ} \mathrm{C}, 16 \%$ higher than other designs. The heat energy increases proportionally with temperature, where a device with adjustable reflector can contain the highest heat energy, which is 131.51 kilojoules, $51.75 \%$ higher than a device without reflector, which has only 41.81 kilojoules. At the same time, the latent heat required to evaporate the water into the mother phase decreases from 3.591 kilOjoules $/ \mathrm{kg}$ to 3.538 kilojoules/kg for a device with an adjustable reflector. Overall, the settling device with adjustable reflector can improve the desalination efficiency, reducing the salinity of seawater to $123 \mathrm{ppm}$, which is $98 \%$ lower than the original value of seawater. This shows that this device can desalinate seawater and turn it into a very safe drinking water. 


\section{Acknowledgement}

This research was funded by Final Year Project Fund and STRG grant (str19024) from Universiti Kuala Lumpur.

\section{References}

[1] Rahman, M. Tauhid Ur, Md Rasheduzzaman, Md Arman Habib, Afzal Ahmed, Syed Mohammed Tareq, and Shah Md Muniruzzaman. "Assessment of fresh water security in coastal Bangladesh: An insight from salinity, community perception and adaptation." Ocean \& Coastal Management $137 \quad$ (2017): 68-81. https://doi.org/10.1016/j.ocecoaman.2016.12.005

[2] Ni, George, Seyed Hadi Zandavi, Seyyed Morteza Javid, Svetlana V. Boriskina, Thomas A. Cooper, and Gang Chen. "A salt-rejecting floating solar still for low-cost desalination." Energy \& Environmental Science 11, no. 6 (2018): 1510-1519. https://doi.org/10.1039/C8EE00220G

[3] Cotter, James David, Simon N. Thornton, Jason KW Lee, and Paul B. Laursen. "Are we being drowned in hydration advice? Thirsty for more?." Extreme Physiology \& Medicine 3, no. 1 (2014): 1-16. https://doi.org/10.1186/20467648-3-18

[4] Ahmed, Farah Ejaz, Raed Hashaikeh, and Nidal Hilal. "Hybrid technologies: The future of energy efficient desalination-A review." Desalination 495 (2020): 114659. https://doi.org/10.1016/i.desal.2020.114659

[5] Al-Amshawee, Sajjad, Mohd Yusri Bin Mohd Yunus, Abdul Aziz Mohd Azoddein, David Geraint Hassell, Ihsan Habib Dakhil, and Hassimi Abu Hasan. "Electrodialysis desalination for water and wastewater: A review." Chemical Engineering Journal 380 (2020): 122231. https://doi.org/10.1016/i.cej.2019.122231

[6] Godart, Peter. "Design and simulation of a heat-driven direct reverse osmosis device for seawater desalination powered by solar thermal energy." Applied Energy $284 \quad$ (2021): 116039. https://doi.org/10.1016/i.apenergy.2020.116039

[7] Ghenai, Chaouki, Dania Kabakebji, Ikram Douba, and Ameera Yassin. "Performance analysis and optimization of hybrid multi-effect distillation adsorption desalination system powered with solar thermal energy for high salinity sea water." Energy 215 (2021): 119212. https://doi.org/10.1016/i.energy.2020.119212

[8] Ewis, Karem Mahmoud. "Effects of Variable Thermal Conductivity and Grashof Number on Non-Darcian Natural Convection Flow of Viscoelastic Fluids with Non Linear Radiation and Dissipations." Journal of Advanced Research in Applied Sciences and Engineering Technology 22, no. 1 (2021): 69-80. https://doi.org/10.37934/araset.22.1.6980

[9] Ismail, Alice Sabrina, Hazrina Haja Bava Mohidin, Aminatunzuhariah Megat Abdullah, and Mohd Nazim Ahyaruddina. "The Effectiveness of Envelope Design in High Rise Office Building using Exterior Wall Cladding as Green Technology Solutions in Malaysia's Urban Context." Journal of Advanced Research in Applied Sciences and Engineering Technology 16, no. 1 (2019): 1-9.

[10] Saengsikhiao, Piyanut, Juntakan Taweekun, Kittinan Maliwan, Somchai Sae-ung, and Thanansak Theppaya. "The Green Logistics Idea Using Vacuum Insulation Panels (VIPs) For Freezer Logistics Box in Normal Truck." Journal of Advanced Research in Applied Sciences and Engineering Technology 21, no. 1 (2020): 15-21. https://doi.org/10.37934/araset.21.1.1521

[11] Hassan, Zulkurnain, Mohd Suffian Misaran@Misran, Nancy Julius Siambun, Ag Sufiyan Abd Hamid, and Mohd Amran Madlan. "Feasibility of using Solar PV Waste Heat to Regenerate Liquid Desiccant in Solar Liquid Desiccant Air Conditioning System." Journal of Advanced Research in Experimental Fluid Mechanics and Heat Transfer 2, no. 1 (2020): 10-16.

[12] Oo, Ye Min, Makatar Wae-hayee, and Chayut Nuntadusit. "Experimental and Numerical Study on the Effect of Teardrop Dimple/Protrusion Spacing on Flow Structure and Heat Transfer Characteristics." Journal of Advanced Research in Experimental Fluid Mechanics and Heat Transfer 2, no. 1 (2020): 17-32.

[13] Okampo, Ewaoche John, and Nnamdi Nwulu. "Optimisation of renewable energy powered reverse osmosis desalination systems: A state-of-the-art review." Renewable and Sustainable Energy Reviews 140 (2021): 110712. https://doi.org/10.1016/i.rser.2021.110712

[14] Abdullah, Amira Lateef, Suhaimi Misha, Noreffendy Tamaldin, Mohd Afzanizam Mohd Rosli, and Fadhil Abdulameer Sachit. "Hybrid Photovoltaic Thermal PVT Solar Systems Simulation via Simulink/Matlab." CFD Letters 11, no. 4 (2019): 64-78.

[15] Samsudin, Sheikh Saiful Azam, Abdul Muin Shaari, Kamil Abdullah, and Mohd Faizal Mohideen Batcha. "Potential of Utilizing Solar Chimney as an Energy Efficiency Measure in Malaysian Hospitals." CFD Letters 12, no. 4 (2020): 90-99. https://doi.org/10.37934/cfdl.12.4.9099

[16] Setyawan, EkoYohanes, Farel H. Napitupulu, and Himsar Ambarita. "Study on the characteristics of a natural vacuum desalination system using solar energy as energy sources." International Journal of Mechanical and Mechatronics Engineering IJMME-IJENS 18, no. 05 (2018): 21-32. 
[17] Hassanein, Soubhi A., and M. Attalla. "Parametric Study on a Solar Still Located in Aswan, Egypt of Hot and Dry Climate." International Journal of Engineering \& Technology IJET-IJENS 13, no. 01 (2013): 46-51.

[18] Khanfoos, Husam N., Qays A. Rashak, and Ala'a A. Jassim. "Parametric study of solar energy desalination system." International Journal of Mechanical \& Mechatronics Engineering IJMMEE-IJENS 18, no. 02 (2018): 64-76. 